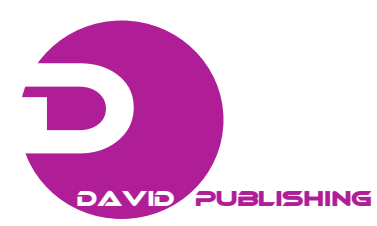

\title{
Influence of Hydrostatic Pressure on Compressive Strength of Self-consolidating Concrete
}

\author{
Elżbieta Horszczaruk ${ }^{1}$, Piotr Brzozowski ${ }^{1}$, Grzegorz Adamczewski ${ }^{2}$ and Tomasz Rudnicki ${ }^{3}$ \\ 1. Faculty of Civil Engineering and Architecture, University of Technology Szczecin, Szczecin 70-311, Poland \\ 2. Faculty of Civil Engineering, Warsaw University of Technology, Warszawa 00-637, Poland \\ 3. Faculty of Civil Engineering and Geodesy, Military University of Technology, Warszawa 00-908, Poland
}

\begin{abstract}
The design of unique chamber, in which the SCUWC (self-consolidating underwater concrete) can be tested under the impact of the hydrostatic pressure from $0.1 \mathrm{MPa}$ to $0.5 \mathrm{MPa}$, is presented in the paper. The results of the preliminary tests of the effect of the hydrostatic pressure on the compressive strength of SCUWC were shown. The impact of the hydrostatic pressure on the compressive strength values of test specimens has been confirmed. There has been an increase in the strength of the specimens taken from the upper parts of the concrete samples. As it can be seen from the preliminary research, the differences in compressive strength are related to the differences that occur in the size and distribution of air voids in the samples taken from upper and lower parts of the test specimens. On the basis of the carried out investigations of the compressive strength, it can be concluded that the hydrostatic pressure has a favorable effect on the compressive strength of the tested specimens of SCUWC. Increase of the compressive strength is observed mostly in the upper layers of the samples. Preliminary analysis of the quantity and distribution of air pores in the samples of concrete subjected to pressure $0.5 \mathrm{MPa}$ confirms the positive impact of the hydrostatic pressure on the layers close to the surface indicated by the absence of large air voids above $1,500 \mu \mathrm{m}$ and by reducing the quantity of air pores of size above $300 \mu \mathrm{m}$.
\end{abstract}

Key words: Compressive strength, hydrostatic pressure, self-consolidating concrete, underwater concrete, air voids.

\section{Introduction}

The problem of investigation of underwater concretes under hydrostatic pressure still remains unresolved due to the lack of the appropriate testing equipment. The only solution encountered in the literature is the chamber for testing a washout resistance of underwater concrete mix under pressure [1]. In the literature, there is no analysis of the effect of the hydrostatic pressure on the durability of the structural underwater concrete and the durability of the contact layer between the repair material, made of the underwater concrete and virtually non-deformable substrates which are the massive hydraulic structures, foundations or bridge heads.

The characteristic feature of the composition of the underwater concrete mixes is necessary for the

Corresponding author: Elżbieta Horszczaruk, Ph.D., research fields: concrete technology and nanomaterials in concrete. E-mail: elzbieta.horszczaruk@zut.edu.pl. utilization of the AWA (anti-washout admixtures). The AWA admixtures improve the cohesion of the concrete mix, preventing the bleeding and segregation of the mix and the binder washout during underwater concreting [2, 3]. Because of the lack of techniques for compacting underwater concrete, and the often long distance between the concrete plant and the place of concreting, SCC (self-consolidating concrete) mixes or ASCC (almost self-consolidating concrete) mixes [2-5] are required. The requirements regarding to the mix consistency and necessity of using of the large amount of the binder make the HRWRA (high-range water-reducing admixture) the second basic component of the underwater concretes [6]. A try of determination of the effect of the hydrostatic pressure on the properties of UWC (underwater concrete) mixes has been presented by Assaad et al. [7]. However, there is no information about the effect of the hydrostatic pressure on the properties of the 
hardened UWC, its structure or strength development in time.

A structure and principle of operation of the tank for testing the underwater concretes under hydrostatic pressure have been presented in this paper. The underwater concrete tested in the chamber was designed as the ASCC concrete. The results of testing the compressive strength after 7 and 28 days of curing in the chamber are presented. The temperature of the concrete during its curing under the hydrostatic pressure from $0.1 \mathrm{MPa}$ to $0.5 \mathrm{MPa}$ has also been measured. The authors analyzed the pores size distribution in the tested concretes. These values were correlated as the function of the hydrostatic pressure and the placement of the specimens in relation to the surface of contact with water.

\section{Experimental Work}

\section{Portland cement CEM I $42.5 \mathrm{~N}-\mathrm{HSR} / \mathrm{NA}$} conforming to EN 197-1 [8] with low heat of hydration and normal-early-strength was used in this study. The surface area of the cement (Blaine) and specific weight were $388 \mathrm{~m}^{2} / \mathrm{kg}$ and $3,150 \mathrm{~kg} / \mathrm{m}^{3}$, respectively. The chemical composition of the cement is presented in the Table 1. A powdered polymer-based stabilizing AWA and naphthalene-based HRWRA with specific gravities $900 \mathrm{~kg} / \mathrm{m}^{3}$ and $1,160 \mathrm{~kg} / \mathrm{m}^{3}$, respectively, were incorporated into the concrete mix. Natural sand and gravel aggregate with nominal maximum particle size of $16 \mathrm{~mm}$ were employed. Their bulk specific gravities were $2,720 \mathrm{~kg} / \mathrm{m}^{3}$ and $2,620 \mathrm{~kg} / \mathrm{m}^{3}$, respectively. The washout mass loss, determined using the CRD C 61 [9] test method, and slump flow were $5.9 \%$ and $500 \mathrm{~mm}$, respectively, after $60 \mathrm{~min}$.
The mix proportions are presented in Table 2 .

\subsection{Apparatus}

The testing apparatus (Fig. 1) consists of the bottom, bell-shaped part, stiffened with four ribs and the top part in the form of cylinder with ellipsoidal cover. The PVC (polyvinylchloride) mould for the tested concrete, of the total volume $21 \mathrm{dm}^{3}$, is placed inside the bottom part. The top part of the tank is provided with the centrally fixed loading pipe of the internal diameter $100 \mathrm{~mm}$, which is used to supply the concrete mix and ends with the collar closed by the flat bottom with steel bolts. In the top part of the tank, there are also the compressed air inlet, water inlet, manometer, safety valve, vent valve, overflow valve and pressure controller. The height of the top part of the tank is selected in such a way that the water level in the tank is constant and equal to $1.0 \mathrm{~m}$ from the upper edge of the bottom part of the tank. The maximum working pressure in the tank is $0.5 \mathrm{MPa}$ and the permissible pressure is $0.6 \mathrm{MPa}$. The pressure may be controlled with accuracy of $0.01 \mathrm{MPa}$. Special construction of the bottom of the tank makes it possible to screw in the plug with the thermocouple and measure the temperature of the concrete during the curing under pressure.

\subsection{Procedure}

After placing the mould inside the bottom part of the tank and fixing both parts, the tank was filled with water. Then about $21 \mathrm{dm}^{3}$ of the concrete mix was poured into the tank through the loading pipe. The excess of water was removed through the overflow valve. The cover of the upper collar was fixed and the chosen pressure was applied. The tests have been

Table 1 Chemical composition of Portland cement (mass \%).

\begin{tabular}{|c|c|c|c|c|c|c|c|c|c|c|c|}
\hline \multicolumn{2}{|l|}{ Material } & $\mathrm{SiO}_{2}$ & $\mathrm{Al}_{2} \mathrm{O}_{3}$ & $\mathrm{Fe}_{2} \mathrm{O}_{3}$ & $\mathrm{CaO}$ & $\mathrm{MgO}$ & $\mathrm{SO}_{3}$ & $\mathrm{Na}_{2} \mathrm{O}_{\text {eq }}$ & $\mathrm{K}_{2} \mathrm{O}$ & $\mathrm{Cl}^{-}$ & Loss on ignition \\
\hline \multicolumn{2}{|c|}{ CEM I 42.5N-HSR/NA } & 21.07 & 3.11 & 4.12 & 63.77 & 0.58 & 3.2 & 0.29 & 0.37 & 0.071 & 2.52 \\
\hline Mixture & \multicolumn{2}{|c|}{ Cement } & \multicolumn{2}{|l|}{ Water } & \multicolumn{2}{|l|}{ Sand } & \multicolumn{2}{|c|}{ Gravel } & AWA & & HRWRA \\
\hline Mix proportions & \multicolumn{2}{|l|}{530} & \multicolumn{2}{|l|}{212} & \multicolumn{2}{|l|}{593} & \multicolumn{2}{|c|}{1024} & 4 & & 5.25 \\
\hline
\end{tabular}




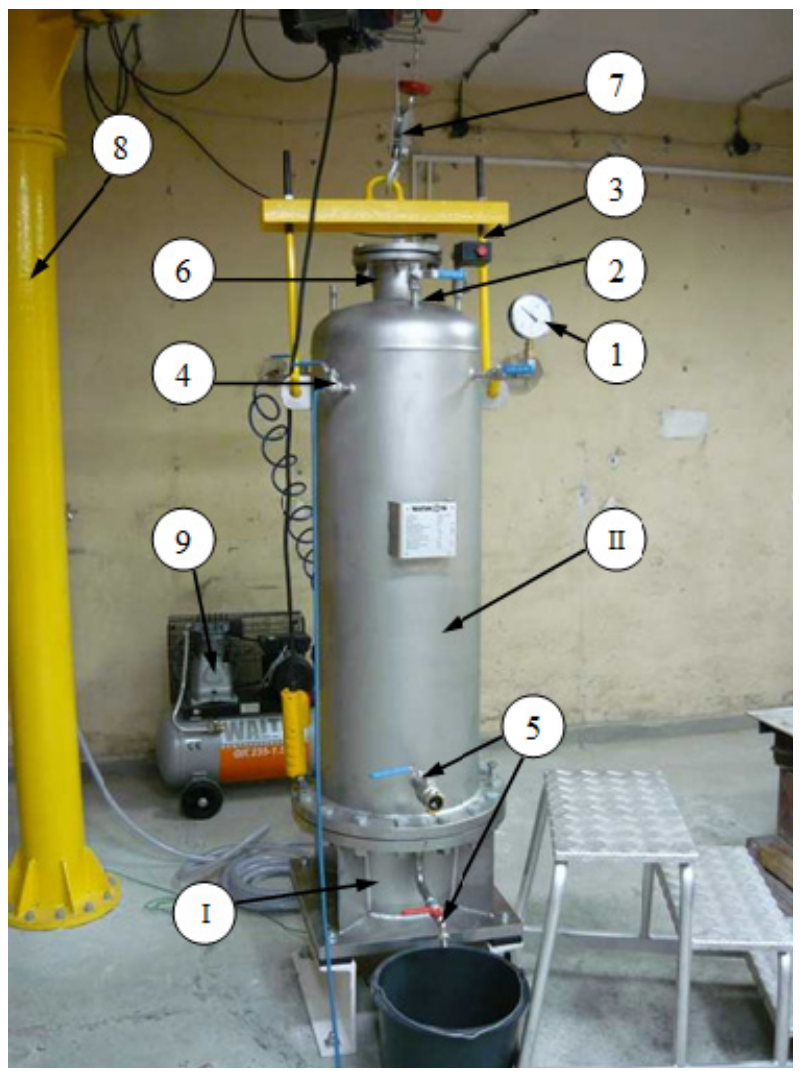

Fig. 1 Test apparatus.

I-bottom part of tank; II-top part of tank; 1-manometer; 2-vent valve; 3-pressure controller; 4-overflow valve; 5-outlet valves; 6-loading pipe; 7-winch hook; 8-crane; 9 - compressor.

conducted for the values of the hydrostatic pressure from $0.1 \mathrm{MPa}$ to $0.5 \mathrm{MPa}$, with the step equal to 0.1 $\mathrm{MPa}$. The concretes were cured in the tank for 7 and 28 days. After finishing the test, the compressor was turned off, the air was evacuated and the tank was emptied from water. After removing the top part of the tank, the mould with the tested concrete was taken out. The $100 \mathrm{~mm}$ cubes for the strength determination as well as the specimens for the microstructural investigation were cut from the above described sample (Fig. 2). Half of the cubes were tested in compression immediately after cutting (thus, the compressive strength after 7 days under pressure was determined). During the cutting of the specimens for the strength testing, the places of taking the specimens from the sample were marked as $\mathrm{T}$ for the top part of the sample and B for the bottom part of the sample. Up to eight cubes were cut from one sample. The obtained values of the compressive strength of the concretes cured under pressure have been compared to the results of the tests performed on the cubes cut from the sample of the concrete made in the similar 22 $\mathrm{dm}^{3}$ mould, stored in the water at the temperature 20 ${ }^{\circ} \mathrm{C}$ but without the pressure. The temperature of the concrete cured in the mould under pressure was recorded for 7 days.

The characteristics of the pores size distribution in the specimens taken from the tested UWC have been determined according to the European Standard PN-EN 480-11 [10] (European equivalent of the standard ASTM C 457 [11]). The measurements of the air pores structure have been carried out using the image analysis system.

\section{Results and Discussions}

Compressive strength results of the concrete specimens after 7 days of curing under the hydrostatic pressure are presented in Fig. 3, with respect to the
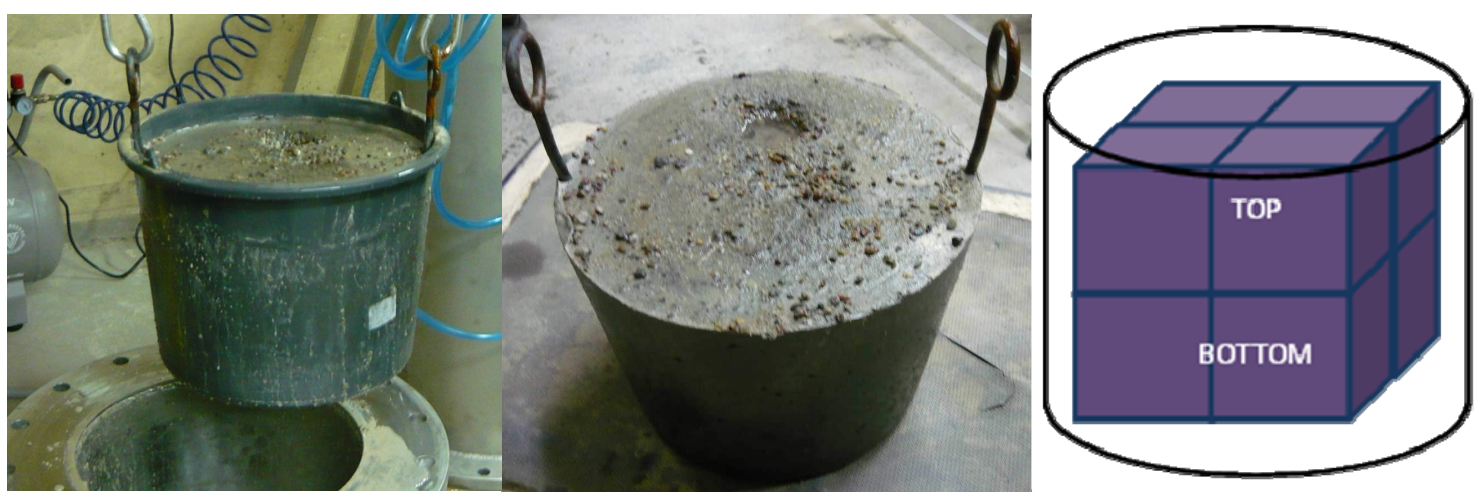

Fig. 2 Concrete sample after curing and scheme of sampling for strength tests. 


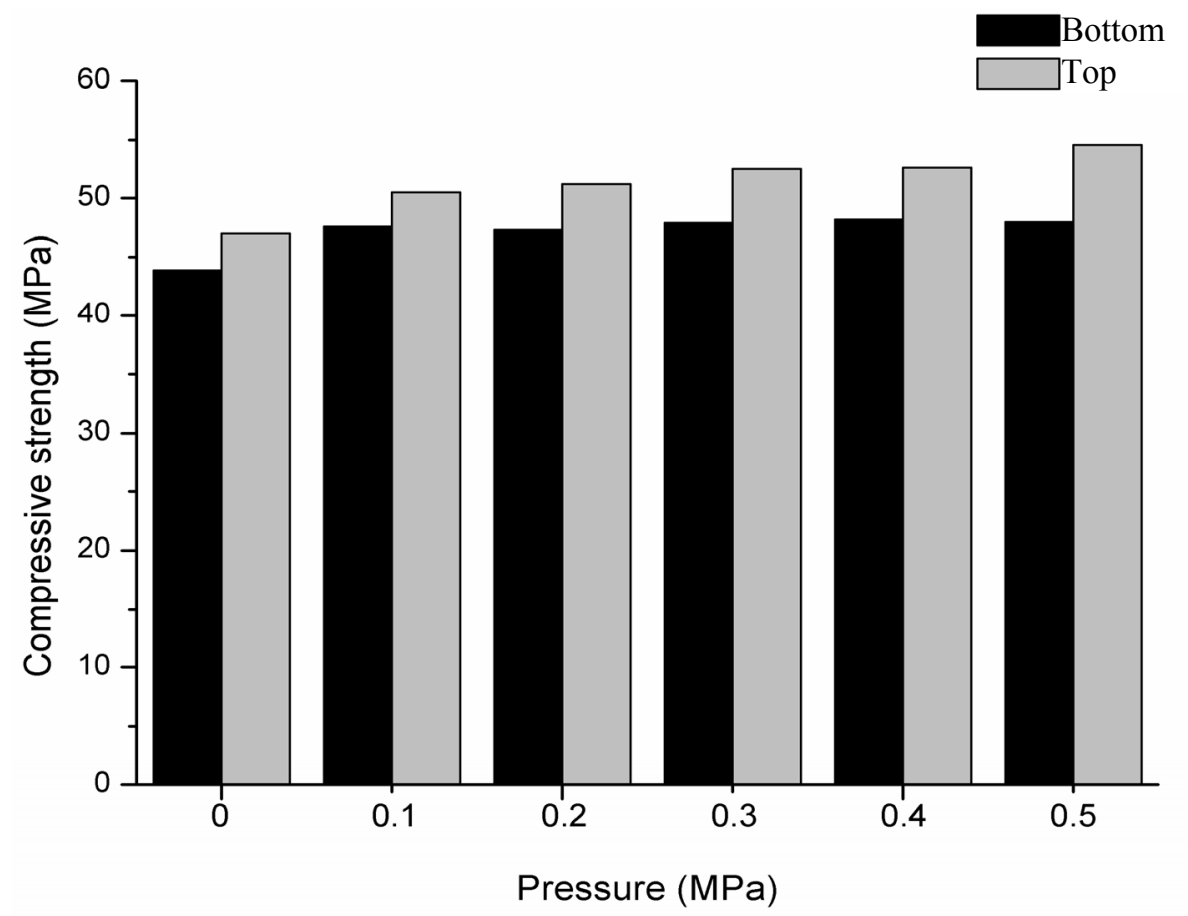

Fig. 3 Compressive strength of specimens after 7 days of curing under hydrostatic pressure.

position of the cut specimens in the concrete sample according to Fig. 2. It has been found out that the cubes cut from the upper part of the sample have higher strength than those cut from the lower part, irrespective of the applied pressure value. The compressive strength is increasing with the growing pressure, however, the impact of the pressure is lower in the case of the specimens cut from the bottom part of the sample.

The results of testing compressive strength of the concrete specimens after 28 days of curing under the hydrostatic pressure are presented in Fig. 4. An increase of 28-day compressive strength with the growing water pressure has been observed. The slight decrease of the strength as compared to the specimens not cured under the hydrostatic pressure has been observed only in the case of the specimens taken from the concrete samples cured under the pressure 0.3 $\mathrm{MPa}$. The strength of the specimens cut from the upper parts of the samples was higher irrespective of the value of the hydrostatic pressure.

The analysis of the pores characteristics in the tested concretes revealed significant differences
(Table 3). The general air content points to the good tightness of the concrete, however, big differences in the air content occur for the specimens cut from the upper and lower parts of the concrete samples. The air content in the specimens taken from the upper layers of the samples is significantly lower than that in the case of the specimens taken from the lower parts of the samples. The large pores of the size 2,000 4,000 m, which are the result of entrapping air during casting, have been observed only in the specimens taken from the lower parts of the tested concretes. No pores of the diameters above $1,500 \mathrm{~m}$ have been observed in the specimens taken from the upper layers of the concrete samples. This explains the higher compressive strength of these specimens as compared to those from the lower parts of the samples. The examples of the pores size distribution in the lower and upper parts of the concrete samples for the pressure $0 \mathrm{MPa}$ and 0.5 MPa are presented in Figs. 5 and 6.

The analysis of temperature development in the tested concretes shows that the time of hydration is extending with the growing pressure. In the case of the hydrostatic pressure on the level 0.4 0.5 MPa, time 


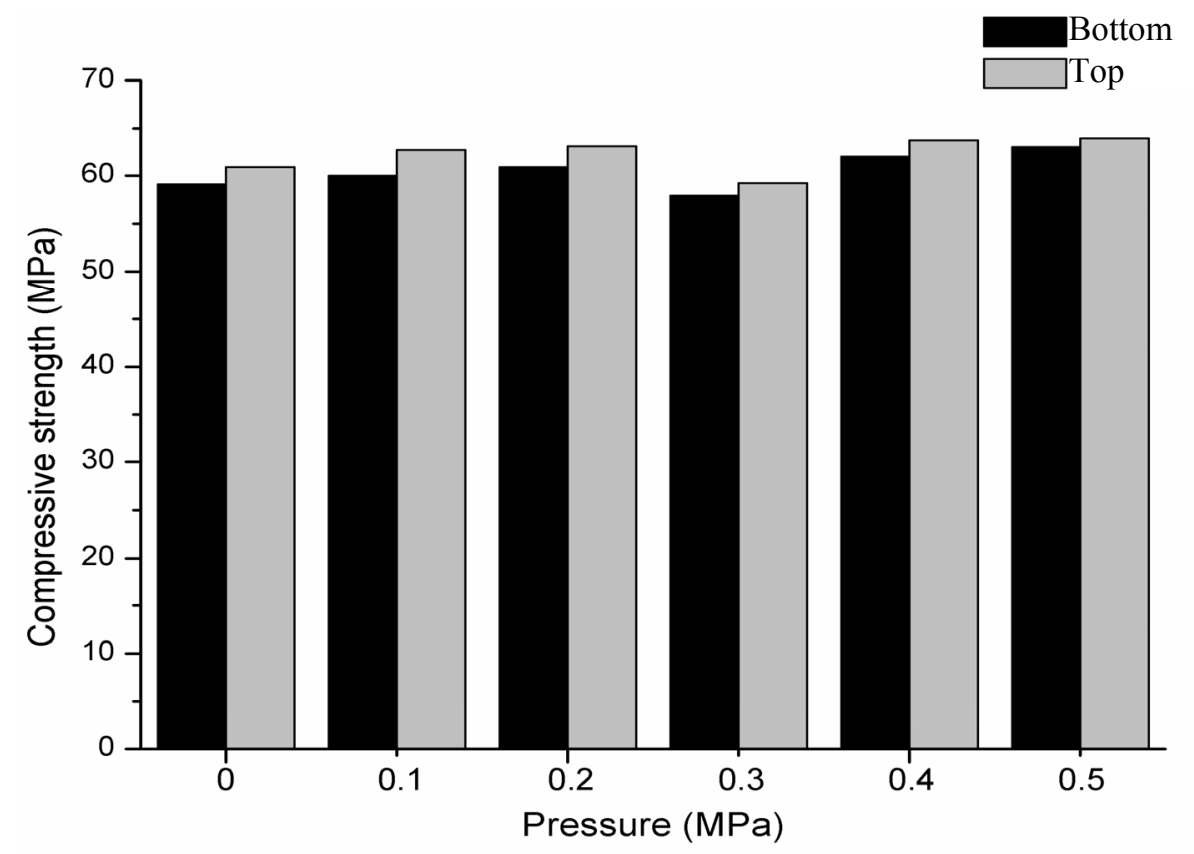

Fig. 4 Compressive strength of specimens after 28 days of curing under hydrostatic pressure.

Table 3 Characteristics of the air pores in the hardened concrete determined according to PN-EN 480-11 [10].

\begin{tabular}{lllll}
\hline Specimen & Air content A (\%) & Specific surface area $\left(\mathrm{mm}^{-1}\right)$ & Spacing factor $(\mathrm{mm})$ & Micro-pores content $\mathrm{A}_{300}(\%)$ \\
\hline $0 \mathrm{MPa}$-bottom & 3.9 & 70.61 & 0.09 & 1.79 \\
$0 \mathrm{MPa}$-top & 2.3 & 68.41 & 0.12 & 1.23 \\
$0.1 \mathrm{MPa}$ - bottom & 1.1 & 35.25 & 0.32 & 0.37 \\
$0.1 \mathrm{MPa}$-top & 0.9 & 32.22 & 0.32 & 0.36 \\
$0.2 \mathrm{MPa}$ - bottom & 1.6 & 81.77 & 0.11 & 1.06 \\
$0.2 \mathrm{MPa}$-top & 0.4 & 66.95 & 0.23 & 0.18 \\
$0.3 \mathrm{MPa}$-bottom & 1.3 & 88.95 & 0.11 & 0.94 \\
$0.3 \mathrm{MPa}$-top & 0.5 & 72.39 & 0.20 & 0.24 \\
$0.4 \mathrm{MPa}$-bottom & 1.8 & 72.42 & 0.12 & 1.16 \\
$0.4 \mathrm{MPa}$-top & 0.5 & 83.38 & 0.17 & 0.36 \\
$0.5 \mathrm{MPa}$-bottom & 2.4 & 71.48 & 0.11 & 0.95 \\
$0.5 \mathrm{MPa}$-top & 1.3 & 78.59 & 0.13 & 0.86 \\
\hline
\end{tabular}

to achieve the maximum temperature of concrete was prolonged even by an hour. The cooling of the concrete as well as the growth of temperature were milder at the higher pressure than at the pressure 0 0.2 MPa. However, due to the difficulties with maintaining the uniform ambient conditions of the experiment performance, i.e., water temperature, temperature of the concrete mix in the time of casting, 24-hour changes of temperature in the room, time from the moment of mixing as well as the limited number of the measurements, these results should be treated as estimated ones. The examples of the temperature development for the concretes cured under the hydrostatic pressure $0.1 \mathrm{MPa}$ and $0.5 \mathrm{MPa}$ are presented in Fig. 7.

\section{Conclusions}

The following conclusions can be drawn from the aforementioned test results and discussions:

(1) The hydrostatic pressure has a favorable effect on the compressive strength of the tested specimens of the underwater concretes. The growth of the compressive strength is observed mainly in the layers that are directly in contact with the pressure source of 


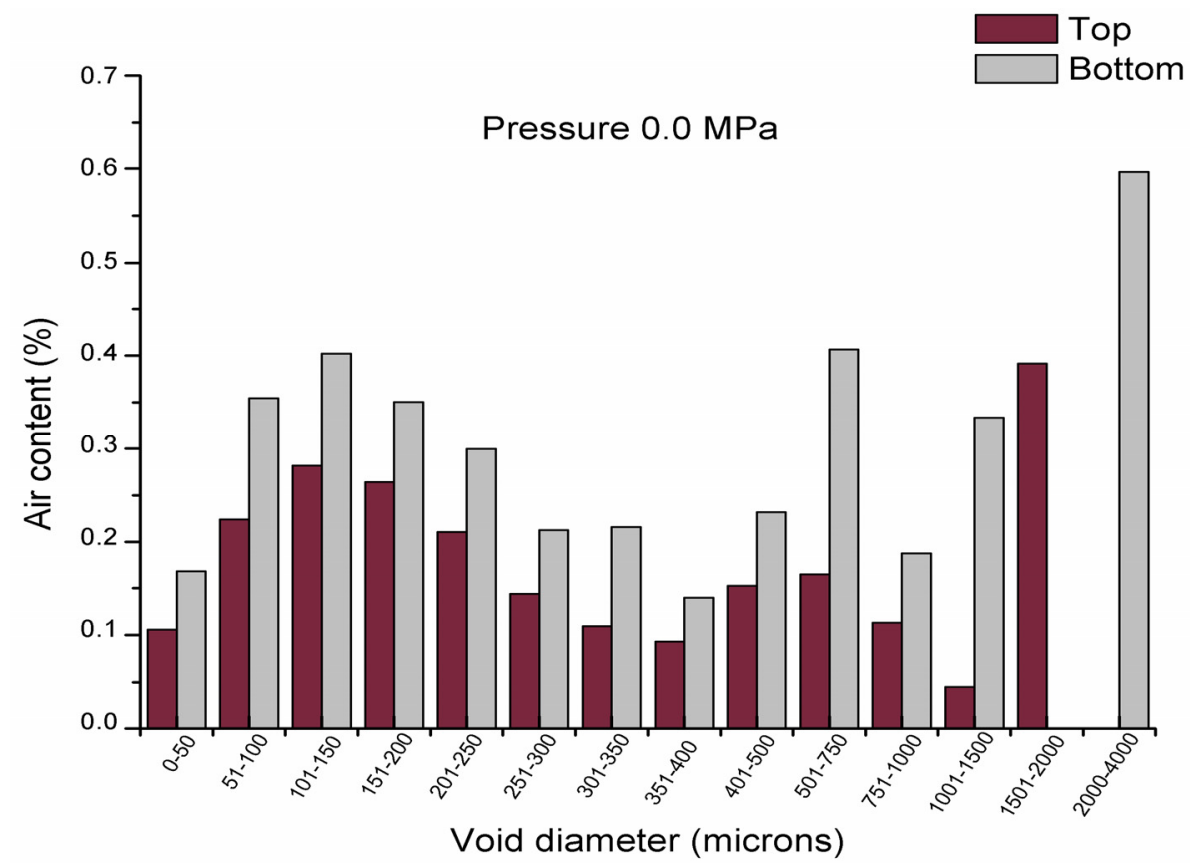

Fig. 5 Ranges of pores diameters for the specimens cured under hydrostatic pressure 0.0 MPa.

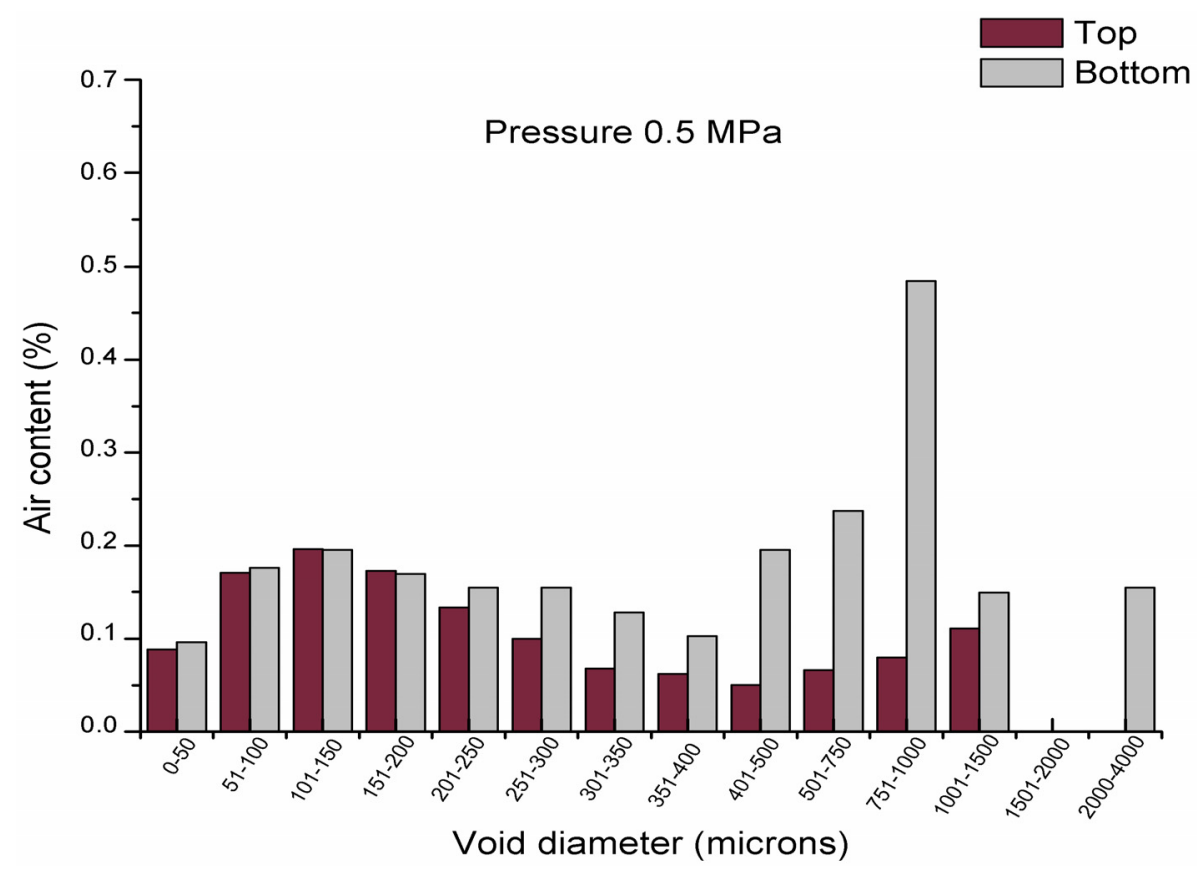

Fig. 6 The ranges of pores diameters for the specimens cured under hydrostatic pressure $0.5 \mathrm{MPa}$.

the tested concretes;

(2) The analysis of the content and size distribution of the air pores in the tested specimens made of the concretes cured under the hydrostatic pressure have confirmed the favorable effect of the pressure on the superficial layers of concrete. This is confirmed by observed lack of the large pores above $1,500 \mathrm{~m}$ in the tested specimens and decrease of the content of the pores above $300 \mathrm{~m}$ with the growing hydrostatic pressure;

(3) The tentative analysis of the temperature development has confirmed the impact of the hydrostatic pressure on the hydration process in the tested concretes. It has been observed that the hydration 


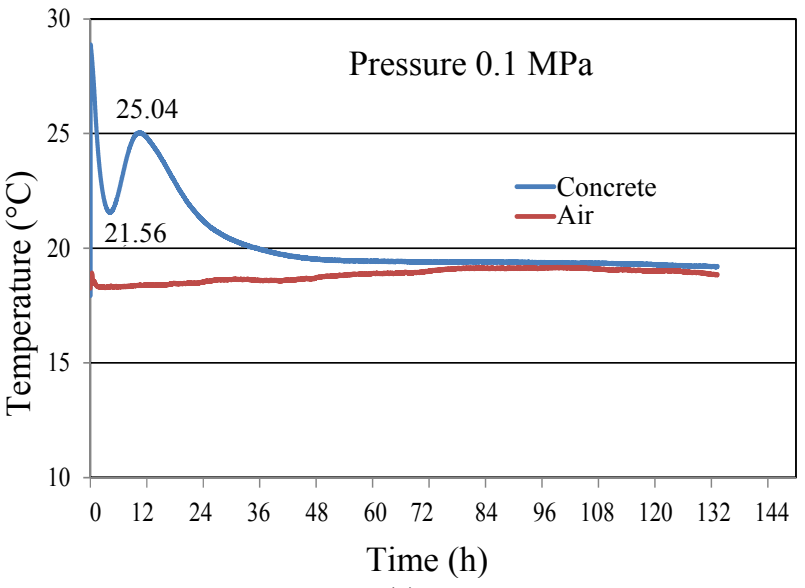

(a)

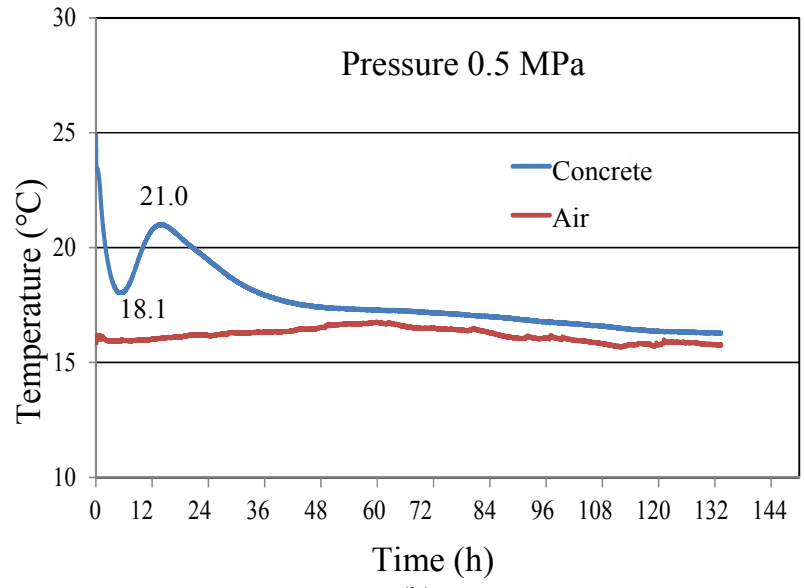

(b)

Fig. 7 Temperature development in the concretes cured in the tank under hydrostatic pressure: (a) 0.1 MPa; (b) 0.5 MPa.

takes longer time and is less rapid at the pressure $0.4 \sim 0.5 \mathrm{MPa}$ than in the case of the concretes cured under the pressure $0 \sim 0.2 \mathrm{MPa}$.

\section{Acknowledgments}

The authors thank to the financial support from National Science Centre (Poland). The research has been supported by the budget funds for the science in years 2011 2013 as the scientific project No. N N506 233139.

\section{References}

[1] K.H. Khayat, J. Assaad, Measurement systems for determining formwork pressure of highly flowable concrete, RILEM (Réunion Internationale des Laboratoires et Experts des Matériaux) Materials and Structures 41 (2008) 37-46.

[2] K.H. Khayat, Effect of anti-washout admixtures on fresh concrete properties, ACI (American Concrete Institute) Materials Journal 92 (2) (1995) 164-171.

[3] B.W. Staynes, Mix design for underwater concrete, in: A. McLeish (Ed.), Underwater Concreting and Repairing, Taylor \& Francis, New York, 1994, pp. 1-19.

[4] M. Sonebi, K.H. Khayat, Effect of mixture composition on relative strength of highly flowable underwater concrete, ACI Materials Journal 98 (5) (2001) 233-236.

[5] K.M. Yousri, Self-flowing underwater concrete mixtures, Magazine of Concrete Research 60 (2) (2008) $1-10$.

[6] K. Khayat, Viscosity-enhancing admixtures for cement-based materials-An overview, Cement and Concrete Composites 20 (1998) 171-188.

[7] J.J. Assaad, Y. Daou, K.H. Khayat, Simulation of water pressure on washout of Underwater concrete repair, ACI Materials Journal 106 (2009) 529-536.

[8] PN-EN 197-1:2012, Cement-Part 1: Composition, Specifications and Conformity Criteria for Common Cements, PKN (Polish Committee for Standardization), Warsaw, 2012.

[9] CRD C61-89A, Test Method for Determining the Resistance of Freshly-Mixed Concrete to Washing Out in Water, U.S. Army Experiment Station, Handbook for Concrete, Vicksburg, 1989.

[10] PN-EN 480-11: 2008, Admixtures for Concrete, Mortar and Grout, Test Methods, Determination of Air Void Characteristics in Hardened Concrete, PKN, Warsaw 2012.

[11] ASTM C 457, Standard Test Method for Microscopical Determination of Parameters of the Air-Void System in Hardened Concrete, Annual Book of ASTM Standards, ASTM, 2011. 